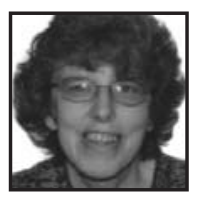

\title{
Collage Inquiry: Creative and Particular Applications
}

\author{
Donna Davis, Education Consultant
}

\section{ABSTRACT}

Collage from "found" visual imagery is widely employed as an accessible medium for expression and illustration in educational, therapeutic, and recreational contexts. Given the history of collage as a strategy of criticism and subversion in the fine arts, visual researchers seek to develop a methodology of collage as a means to knowledge, affording insight into the negotiation and embodiment of media imagery in subjective experience. Highly relevant issues of body image and eating disorders are addressed through the presentation and analysis of a self-study series of collages and life writings. The resulting intuitive "figures" of anorexia demonstrate the creative potential of collage to reconfigure experience excluded from standard texts, and suggest alternative interpretations of both suffering and healing on an individual and cultural level.

$\mathrm{n}$ the last two decades, educational researchers in alternative and artsbased representation have sought to reveal, synthesize and voice realities excluded by the linearity and power dynamics inherent in traditional academic text and analysis (Vaughan, 2005; Davis \& Butler-Kisber, 1999; Eisner \& Barone, 1997; Eisner, 1991). Collage has emerged as a problematic yet exciting strategy for the exploration of memory, imagination and experiential reflection in an increasingly "mediated" world.

Accessible and ubiquitous, photo-collage from "found" media images is widely employed as an expressive and illustrative exercise in educational, therapeutic, and recreational contexts, from media studies to scrapbooking. Often requiring 
only ephemeral, inexpensive materials and a minimal investment in technique, the practice of collage thrives upon the tacit understanding of design and photography pervading a culture dominated by visual media. The automation of such basic operations as "cut," "paste," and "layer" in digital software has further popularized collage processes, reducing the emphasis upon craft, history, genre, and individual "talent" associated with traditional art media such as painting and drawing. Unfortunately, media collage is often regarded as "visual text" or illustration, a means to a corresponding message or lexicon; and many amateur efforts founder at this stage. The collage becomes a visual poem or pun scarcely hiding a verbal one. Yet a simple collage of magazine photos may at the same time evoke inexpressible feeling states that "seep" through the fissures and layers, tugging at what lies below, behind or beyond the choice and arrangement of pictures: an "elsewhere" (Butler-Kisber, 2006).

For many years I have explored collage theory and practice as a research methodology, producing and interpreting complex media collages as a form of visual journal, as both spontaneous reinventions of personal experience and directed critical responses to research issues and texts. As artist/visual researcher, I seek a deeper understanding of the properties of the medium as a means to knowledge, and the conditions under which it presents opportunities for new personal and cultural insight. My interest in collage is primarily grounded in its capacity to disrupt, parody, and challenge the logic and sophism of conventional signifying practices and representations.

\section{Collage Medium: History and Theory}

Historically, the collage/montage aesthetic emerged from popular/folk art origins to become a critical discourse defying the traditional master narratives of authority, mythic individualism, and essentialism in which literature and painting were heavily invested. A medium of the modern era that anticipates the intertextuality of postmodernity, collage has particular applications for the invocation of paradoxical and liminal experience, implying forces in perpetual flux between and among juxtaposed and superimposed elements. It may be useful in fact to regard collage as an organizing principle, conceptual strategy or method rather than an art form per se. In his survey of $20^{\text {th }}$ century collage, art critic Brandon Taylor writes:

Modernity's fragments, some collages suggest, are its history, its residue; they are what is left over when the great feast of consumption has ended for the day, when trading and exchange have ceased and the people have gone home for a rest. 
Collage...allows us to see that it is somewhere between the bright optimism of the official world and its degraded material residue, that many of the exemplary, central experiences of modernity exist. (Taylor, 2004, p. 9)

On the one hand, the making of media collage is an appropriation and celebration of mass culture, its endlessly plastic activities of production, reproduction, and commodification; on the other, it is driven at an intensely personal level, visceral and erotic, not only in the choice of images as from an immense virtual buffet, but also in the continual destruction and reparation of objects, a "metaphor of universal becoming" (Kuspit, 1983, p. 506). While a collage can be constructed according to a precise, premeditated plan, media collage is typically composed in a more impulsive, fluid, and expedient manner, a method which at once accesses and undermines the hierarchies of signs, effectively exposing them as both compulsory and arbitrary. The artistic creation of collage may thus furnish a means to take back a measure of power over spectacular representations and renegotiate them versus everyday experience and identity (Davis, 2000).

In her discussion of visual methodologies, Rose (2001) describes how images are organized to situate the viewer in a particular space and, by extension, a subject position with various attributes of power and desire. Collaged imagery often problematizes this inherent positioning of "scopic regimes." For example, the collagist may exploit the photographic illusion of depth, creating a "window" on a virtual world that apparently obeys traditional pictorial effects of modelling and perspective, only to disorient the viewer through contradictions of image scale, material layering, and figure-ground reversal that evoke the alternative spaces of fantasy or tactility. Notably, Taylor asks if traditional collage is not also intrinsically bound up with the raw manipulation of printed signs as material-a process of resistance requiring the physical rupture of an analogue image/object (Taylor, 2004). Indeed, one may designate collage/bricolage practice as an embodied intervention in the slick visual surfaces of corporate signification, perhaps all the more when it later disowns its physical origin and masquerades among the seamless elite of digital illusion.

\section{Applications to Self Study:Visual Culture, Body Image and Memory}

In 2004, I produced a series of digital prints and a graphic artist's book which incorporated reductive collage imagery in a multivalent poetic narrative. In an introductory statement to these works I wrote: 
As artists we employ different modes of representation sensing intuitively that they enable us to evoke qualities of perception and feeling that written texts exclude. Clearly we seek to bring to consciousness and communicate the tacit knowledge that resides in our subjective experience of life. And as "designers" we may be privileged not only to search out new metaphors on the edge of existing cultural representations, but also to give form to new experiences themselves.

Surely the crux of our human condition is that we live as both symbolic and physical beings...Our actions and responses are not merely registered and catalogued by our minds, but are translated into the chemistry of our brains and written into the functioning of our bodies. Yet even in a culture teeming with eroticized images of the external body, on a personal level we may lack a true voice for our experience of life within a body... When my conscious mind cannot define the mute... gestures of pleasure or pain at the threshold of my awareness, I project the ideal body, its parts and its animal or machine correspondences, as the only evidence of the multiple emotions, memories, and phantasms that remain unsaid. (Davis, 2004, p. 1)

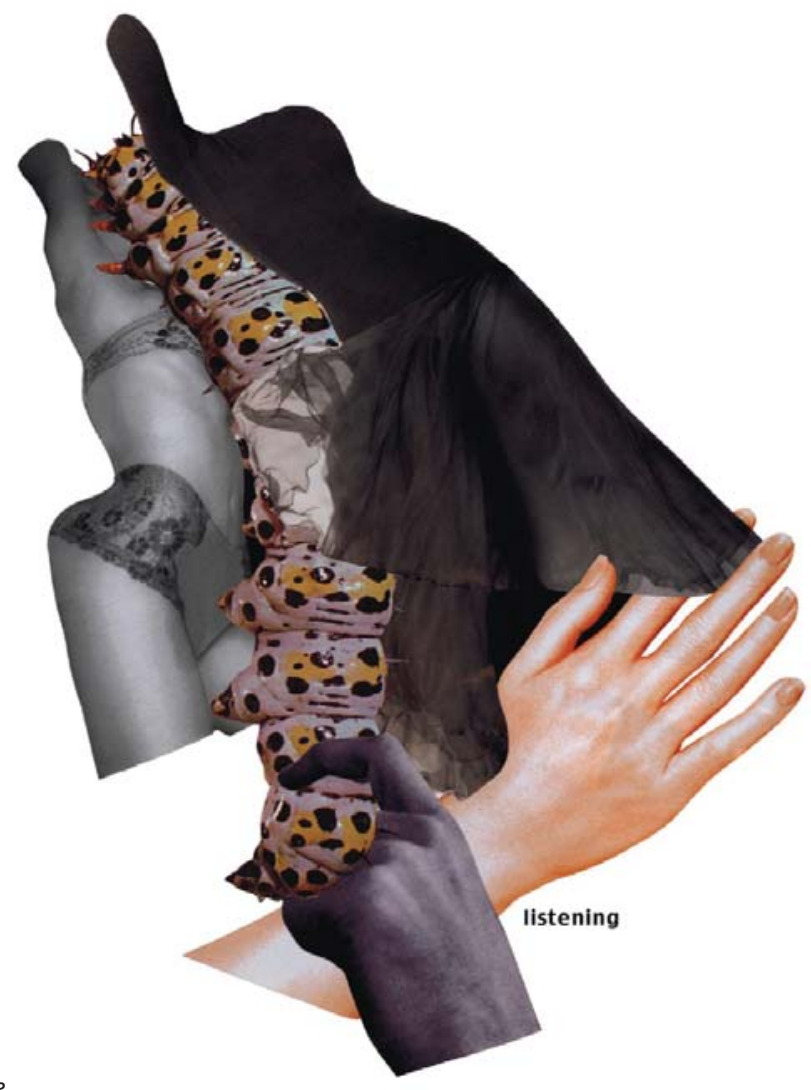


As this commentary indicates, many of these mysterious and intimate artworks haunted me (see above figure). Ultimately I wished to develop and elaborate their content in a more personal and focused way. In April 2007 I created a series of small collages hand-crafted from images found in magazines, books, and other print media, in the context of a self-study/memoir. Rather than trusting the content of the collages primarily to mood, "intuition," or chance, I intended to grapple more consciously, from the outset, with my experiences of eating disorders throughout my adolescence and adult life. I accompanied the visual project with ongoing reflective, interpretive life writing prompted by the collages in process. Thus grounded in intense memories, fantasies, and feelings, my reconstruction of the media imagery through collage might more clearly suggest the extent to which my individual subjectivity had contrived an identity from the poses of different sociocultural discourses. Moreover, I might be challenged to re-imagine or recognize the body-this body, implicitly my body - as site of communication and metaphor, creation and destruction, distortion and illusion, taboo and violation.

It is an unproven truism that fashion and media images, or such images mirrored in the appearances of celebrities, models and performers, promote the relentless pursuit of thinness. This commonsense logic takes the (typically feminine) gaze to be an instrument of passive visual consumption and contagion (Burke, 2006). Yet who knows how the multiple exposures of faces, breasts, weddings, desserts, victims, cellulite, mountain peaks, living rooms, lovers' embraces, flowers, handbags, forest fires, pleasure, penguins, pain relievers, desire, lunar landscapes, blue skies and anguish are processed in the interior spaces of the body and screened onto its communicative surfaces? How is "body image" distilled, and where does this figure reside, in private and public space?

Moreover, current discussions of eating disorders note the prevalence of "Ophelia" discourses around female adolescence, flattening the experience of real persons into tropes of crisis (Mastronardi, 2006). A scenario emerges in which the media construct, and authority figures must rescue or punish, essentially passive women who are judged incompetent to claim or voice their own power (Burke, 2006; Inch \& Morali, 2006; Ferris, 2003). For example, although conventional treatment seldom resolves anorexia, "Pro-Ana" web communities are condemned as deadly traps and shut down, in effect silencing alternative possibilities. (Pro-Ana blogs and forums, originating with sufferers themselves, may be said to not only "discuss" anorexia and bulimia, but also to promote or prescribe the behaviours and attitudes by which pathological objectives can be attained. Thus it is construed by critics that Pro-Ana may in effect advocate suicide. In-depth research and content analysis, however, has 
produced a richer, more diversified profile of a creative, alternative community [Shade, 2003].) Similarly, theorists deplore the demonization of severe cases, which conceals the suffering of "subclinical" and older/chronic anorexics and helps to deny the painful obsession with body image and food in our culture at large. Of course, it is a complementary truism that familial, social, and personality dynamics are the progenitors of eating disorders (Bruch, 1978, pp.26-27). Here, my own experience has belied the popular and therapeutic fictions of recovery despite the sentimental attraction these canonical texts exert.

Collage, created from a synthesis of shattered fragments, realized in an emergent, often randomized composition, arrives at meaning in a very different way-accidentally, capriciously, provocatively, tangentially. Scraps, details, and hints intrude from the periphery, both literally and figuratively. One may thus theorize the relationship of collage to the "margin," admitting the sidelong glance rather than the privileged gaze, and speaking to outlaw experience excluded from representation (Vaughan, 2005). Creativity theorist Edward de Bono, describing lateral thinking, contrasts the definitive "rock logic" of identity to the mutable, indirect "water logic" of intuition and suggestion, that which provides no definitive answer but asks, instead: to where does this flow... what happens next (De Bono, 1999)? In honouring the disconnected, inexplicable, irresolute and relative, collage process engenders an inclusive reality where disintegration, disorder, and even destruction can be coincidental paths to meaningful renewal, and insists that restoration and insight are not easily rationalized and prescribed. Collage, originating through changing visual patterns, perceptually configured and reconfigured, "found" rather than "made," works against the inflexibility of abstracted representations and definitions imposed on a dynamic reality.

South African artist/animator William Kentridge, distinguished for his work with silhouette "processions," sheds further light upon this process of "figuration," where perception provokes the recognition of meaning through the experiential resonance of form:

I did a workshop... at my children's school. They cut or tore roughly the elements of a vertebrate- - head, limbs. torso, pelvis. And they made a dog do a somersault, a dinosaur rearing on its hind legs, a monster hiding its head behind its arm. If we had started the other way, this would have been impossible of course. None of them could say or draw what a dog doing [a] somersault looked like, but all could recognize it as it appeared before them, made by them. (Kentridge, 2004, p.159) 
"Simultaneously, there can be a realization that cognition and representation are inextricably linked....and that different forms of representation can alter perceptibly one's understanding of phenomena..." (Davis \& Butler-Kisber, 1999; Eisner, 1991).

To further contextualize, I note that Malson and other authors have disputed the still-prevalent assumption that anorexia is a monolithic syndrome which overtakes and renders all its victims monotonously the same (Bruch, 1978). Malson's extensive analyses of interviews emphasize the widely varied subject positions that constitute many diverse "figures" of the eating disorder (Ripa di Meana, 1999; Malson, 1998). More radical researchers propose that the "pathology" may present a rare opportunity to work through cognitive and developmental problems at the deepyet explicit-transformative level of bodily and material experience (Garrett, 1998; Ripa di Meana, 1999). It is the sheer difficulty of this undertaking, then, which often leads to tragic fixations and misguided conclusions, and which requires profoundly creative resolution. My thesis - that collage is a methodology analogously suited to the investigation of the personal/social construction of self/body images in a media culture-recommends collage to the (self) study of such recalcitrant subjective issues as eating disorders.

\section{Collage Project:Technique}

Typically my collage work is created mainly from printed images culled from magazines, books, and ephemera such as calendars and cards. Some pictures will be pulled directly from source, others from loosely organized files, previously compiled. For this self-study series I chose to exclude words and original drawings; all collages were devised within approximately $10^{\prime \prime}$ by 8 " rectangles, mostly vertical, and pieces were cut, not torn. Published images from various sources-magazines, books, calendars, etc., dating from the 1970s to the present-were selected and amassed according to simple categorical criteria or descriptors: women, plants and flowers, animals and birds, thinness/fatness, hunger and eating/devouring, food, skeletons and viscera, and landscape or interiors. While at this stage I sought few overt correspondences to personal memories or fantasies, I granted media images their strong emotional bias, letting them to "speak" to me, in effect "hailing" me, as my process notes indicate:

Clearly, I could give free reign to my love of emaciated and mysterious fashionista heroines. Skeletons, anatomical diagrams and x-rays, stilt-legged 
flamingos, herons, and sandpipers were epitomes of thinness. And...the polarity, the temptations of St. Anthony and Christ: Bread, food, particularly vast stretches of lavish desserts and oozing icing and slabs of red meat. With their counterparts in landscape:Yes, deserts, and sugary peaks of crystalline snow, and bloody Outback sunsets. I was drawn to images of deep space, doorways, and holes. I pulled photos of cutlery, shining accomplices of dirty deeds, and of jewellery, not only for the sparkling gems but also for the erotic chains of bondage and hoops of performance that its traditional forms imply...But repellent flesh, and indulgent sloth...came in their most primitive forms, as snail and slug. (D. Davis, process notes, 2007)

In the next phase, I began grouping images and working freely with individual collage layouts. Large pictures were left intact for backgrounds and smaller figures were closely cut out and integrated into prevailing lighting and colour schemes; some of the first trials were abandoned at this stage. Using a découpage technique, bordering images were feathered to downplay edges, and later retouching in Photoshop ${ }^{\circledR}$ would reemphasize "seamlessness."The evolving collages often depicted scenarios or implicit narratives with women and animal "characters." As the collages progressed, many episodes of my adolescent and childhood experience surfaced in relation to particular images or combinations, and I began to write interpretations and vignettes provoked by my recollections. I adopted a new strategy: rather than complete collages in sequence, I left many unfinished compositions "active," enabling me to integrate and reorder new images in a dialogic process among collages and writings.

Fifteen collages were completed in this series. For the purposes of this paper, I am presenting four, preserving their sequential order following figure 1 from my earlier work. My discussions integrate passages from my original process notes and lifewriting/memory work, here framed in a larger critical context. 


\section{The Collages}

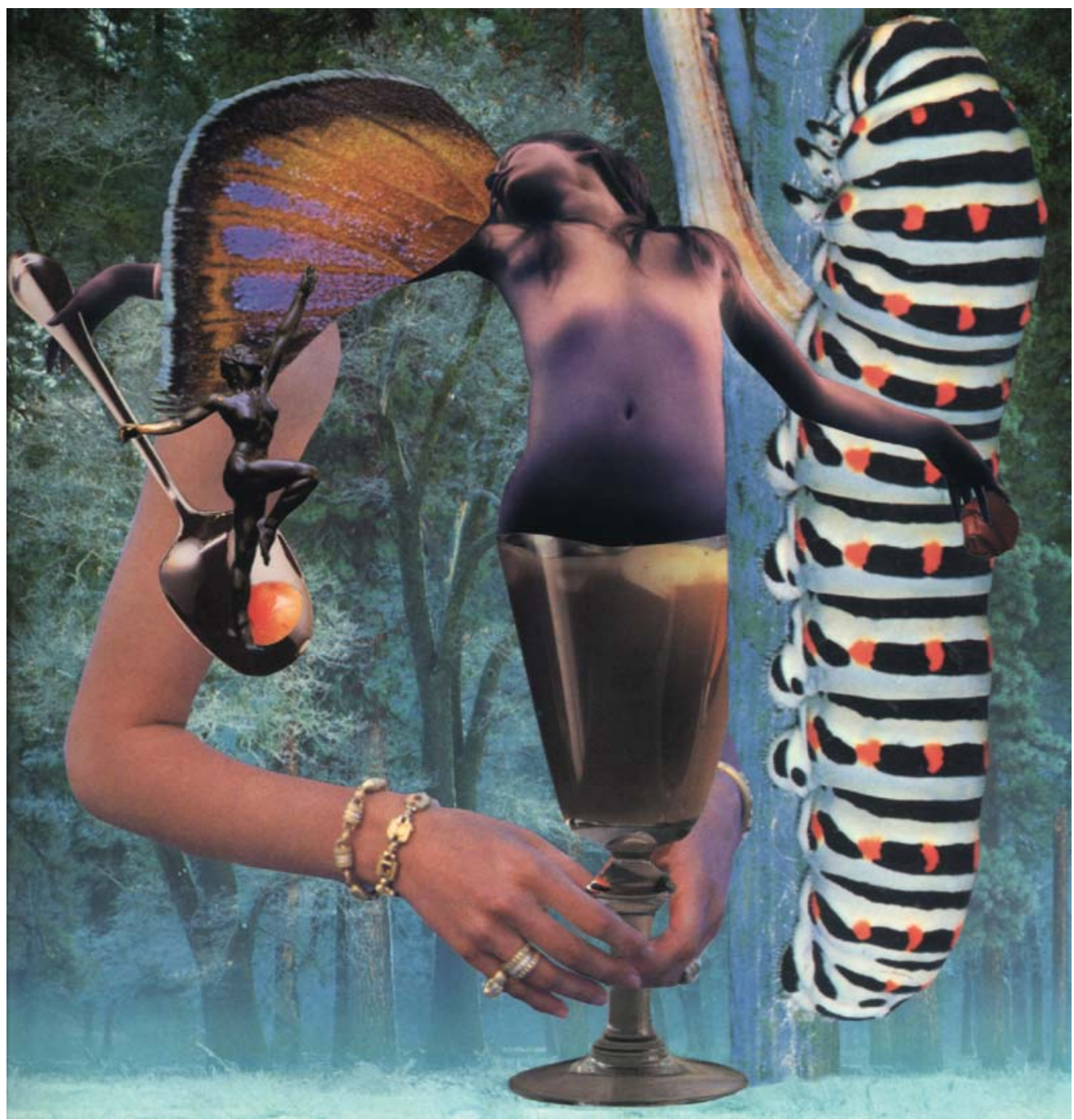

Fig. 2. Incomplete metamorphosis

I am often drawn to butterfly imagery, and in the bookwork collage series I had used a number of pictures of moth and butterfly metamorphosis pulled from the ubiquitous old Life Science and Nature Library of my schooldays in the 60s and 70s. In the Life volume on insects, there is a photo essay that has always provoked a morbid fascination in me. A series of scientific experiments is depicted in which a 
Cecropia moth pupa has been cut in halves and the segments separated by a glass tube. These sadistic manipulations are apparently intended to study how development proceeds or fails depending on chemical intercommunication among the head and other centres of the larval body. Of the three examples, only one, in which the tissue spanning the intersecting tube remains active, leads to a fully metamorphosed moth. Then a full-page photo shows this moth on A Fatal Flight: Instinctively crawling upward to spread its wings, it breaks the thin walls of tissues linking its upper body to its abdomen, and falls to the ground and dies. I can only begin to speculate what macabre cultural impulses underlie the making of this spectacle and fabula in the name of science education. But in context my puzzling earlier title, Incomplete, appears to be an intuitive punt. Incomplete...metamorphosis, as in the case of those hapless insects diddled by science. An untimely intervention in the processes of growth, a moratorium that one can never overcome, dooming all later attempts to fly.

These reflections arose from the inclusion of the caterpillar in this collage; I had pulled the larval images originally as tokens of bloated voraciousness, and realized in the process of assembly their relation to previous work. Here, wanting to expand the nymph's lower body, playing on fears of "middle-aged spread" and sexual power, I inserted the "parfait" glass. And I recalled my mother's insistent mantra: "Everything would be fine if you would just eat."Those adult hands holding the glass: Who drinks from that cup of sorrow now, if not me...transformed now, into my mother's image? A no-exit problematic, lost in a tangled though beautiful Narnia wood covered with sweet, glittery frosting. A scene painted dreamily in hallucinatory, Lucyin-the-Sky-With-Diamonds colours, true again to the palettes of my coming of age.

Weber and Mitchell, through the Image and Identity Collective, have plumbed the relation of stereotypical imagery, narratives, and scenarios to the memory and understanding of personal reality (Weber \& Mitchell, 2004, 1995). Their initial studies indicated that the reductive schema, and the easy repetition and promulgation of such stereotypes, often dominated the imagination at the expense of lived complexity and contradiction. However, my discussion above suggests that the psychic and metaphorical incorporation of media imagery is folded, braided, and layered in unexpected and idiosyncratic ways; the Life photo-essay, the caterpillar as eating machine, play into my childhood interest in real insects but then substitute for deeper, more inchoate desires and fears, now mobilized by juxtapositions and contrasts in the collaged imagery. 


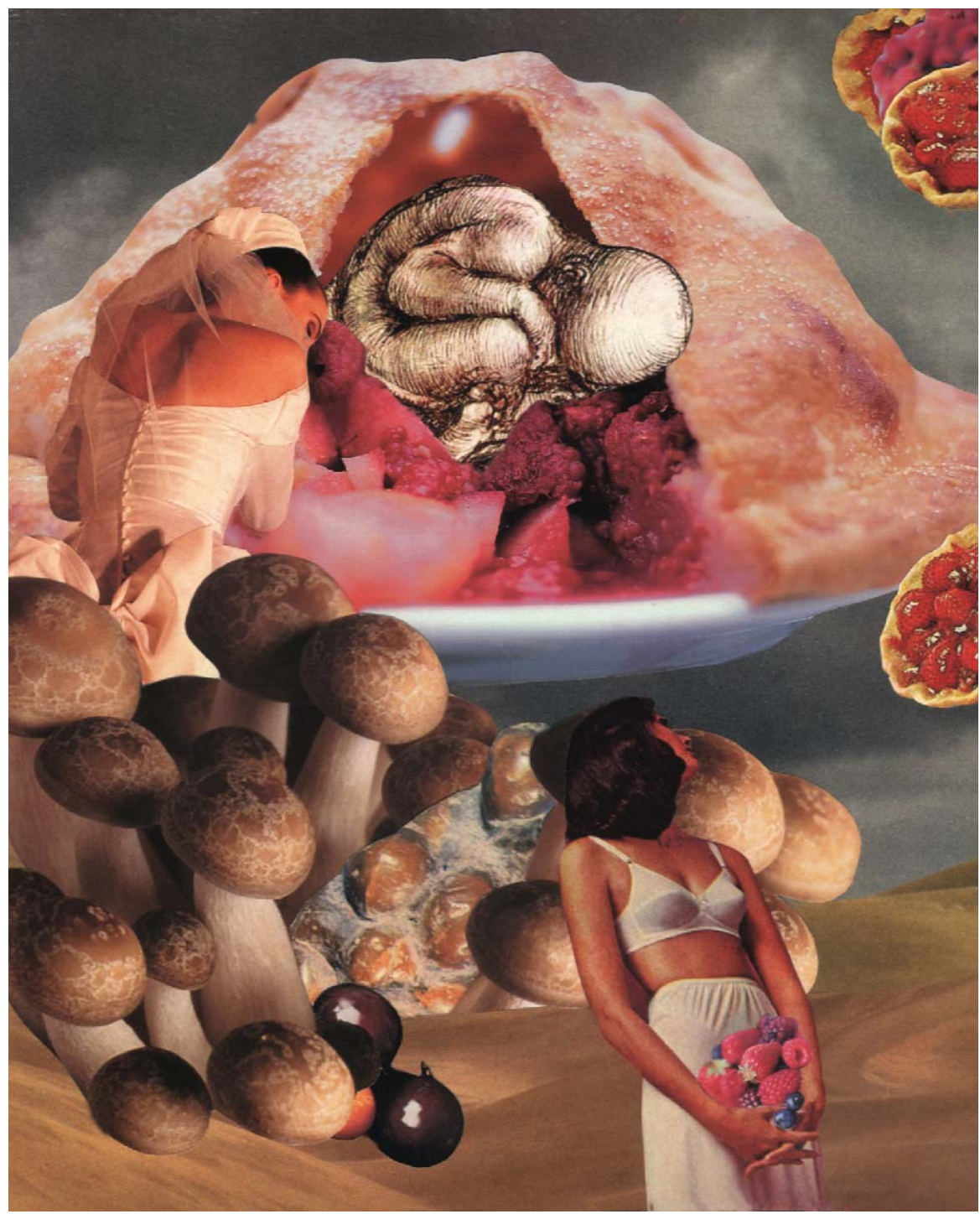

Fig.3: Invasion of the body snatchers

This farcical image, inspired by a classmate's reference to the "monstrous feminine," grew out of my decision to make the pastry on the plate float in the ominous grey sky above the desert sands, leading to the realization that it then resembled a flying saucer. However, I only chose to follow this association to its comic conclusion when faced with the need to fulfill the right side of the image toward which the bride and Da Vinci fetus are turned, though with averted gazes. Now the blissful 
70s woman in the white slip, caught red-handed on the brink of a stain, turns to watch the arrival of the strawberry tarts from outer space.

The Alice in Wonderland mushrooms, ambiguous emblems of food, poison, and decay, partly conceal a Venus of Willendorf-like fetish, and the fetus buried in the raspberry filling similarly follows from the primitive line of proto-reasoning that fantasizes the swellings of pregnancy as invoked by the ingestion of certain magical foods. Anorexia, like pregnancy (and, indeed, wedding preparation) presents itself as demonic alien force that invades the female body and converts an innocent girl into a monster, overtaking her conscious will to employ it for its own sinister, robotic devices. Implicit, but not yet realized here, is the gory eruption of this body as the parasite finally breaks out of its shriveled and decrepit host. Little wonder I reached for some comic relief.

Although anorexia may be characterized in therapeutic accounts as an attempt at alternative selfhood, it is imperative to replace this false attempt with normalization and adjustment to the "real." The anorexic is configured as Other by omnipotent experts and outsider witnesses; and "confessional" authors describe their recovery in similar borrowed terms, in a double alienation that perpetuates the duplicity and splitting said to diagnose the disorder (Hinz, 2006; Ferris, 2003; Bruch, 1978, p. 55). In this collage, the explicit use of visual puns, multiple identifications, and humour-particularly in disarming and conflating the said enemy, food-strive to break the impasse of bad faith. Given the power of collage to override and disrupt established systems of signification, even to break down semiotic codes into chaos, dare we look at anorexia as an embodied bricolage that might join in artful play (Hebdige, 1979)? 


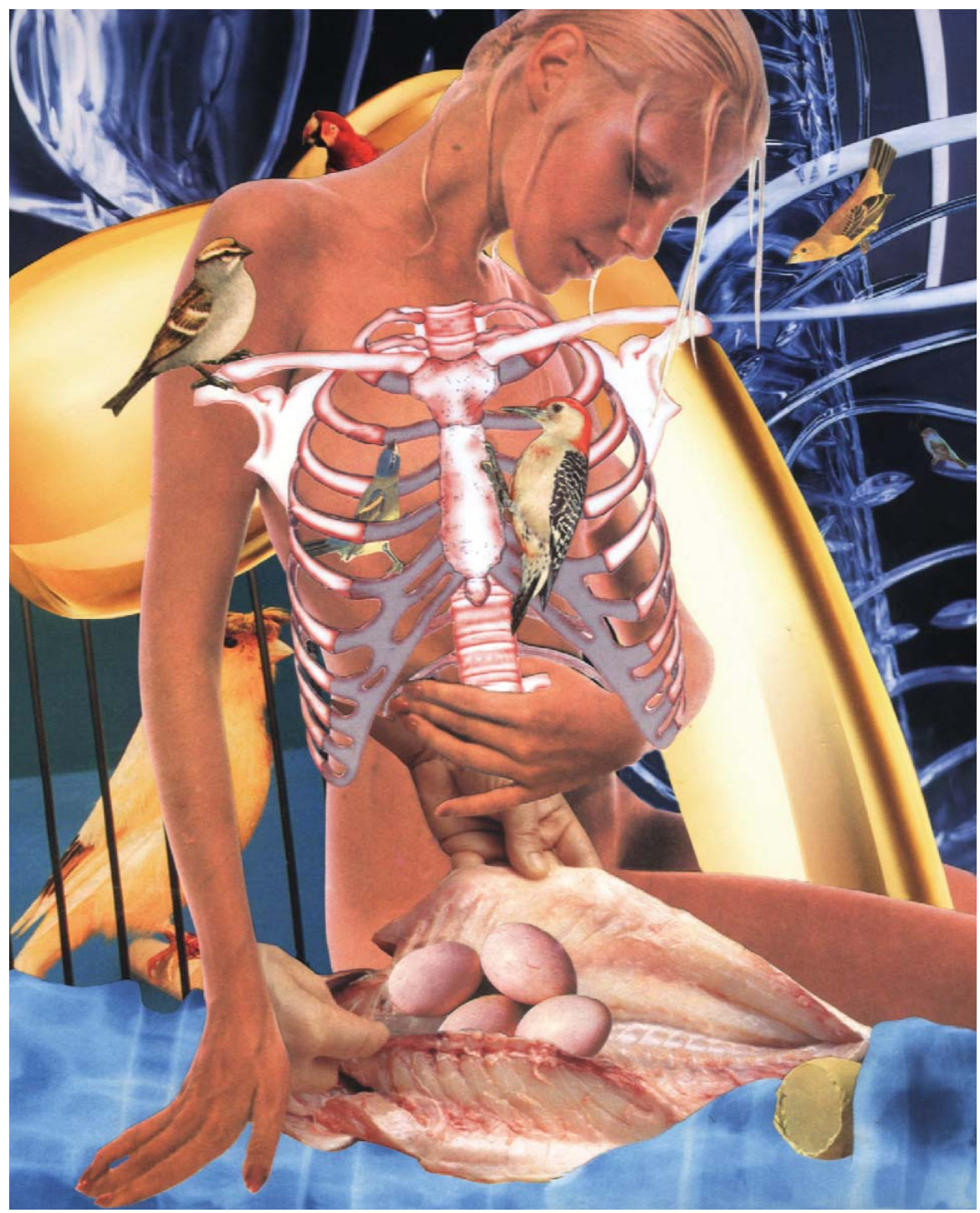

Fig. 4: The gold standard

An image came to her, that she was like a sparrow in a golden cage, too plain and simple for the luxuries of her home...Until then she had spoken only about the superior features of her background; now she began to speak about the ordeal, the restrictions and obligations...She enlarged on the image, that cages are made for big colorful birds who show off their plumage and are satisfied just hopping around in the cage. She felt she was 
quite different, like a sparrow, inconspicuous and energetic, who wants to fly around and take off on its own, who is not made for a cage. (Bruch, 1978, p. 22)

A testimonial from an anorexic teenager inspired this collage; her simile is also the origin of the title to psychotherapist Hilde Bruch's The Golden Cage, an early account of the emergence and treatment of anorexia. Bruch's straightforward explanations that widely skirt the darker complexities of psychoanalysis, her attitude of competence and compassion, evoke the idealized healers of contemporary popular fictions. Yet that sparrow makes me wince. The fable is cited as proof of the patient's ongoing recovery of health, integrity, and thus insight, that she gives voice to her frustration and inadequacy within the "cage" of parental expectations. But was that cage not already represented in the skeletal body converted by a Midas touch to incorruptibility and preciousness? What of the big (fat?) colourful bird who may impersonate a trapped and entrapping mother, and the girl's residual longing to escape, to disappear? The energy of a sparrow will not take one very far; this image of "natural" independence is imbued with qualities of inferiority and domesticity. Content to feed on the few crumbs it is thrown, the sparrow is essentially a scavenger and nuisance.

The anecdote also underscores an early argument that the rise of "Women's Liberation" bore responsibility for the phenomenon of anorexia. Girls were faced with an array of choices too overwhelming to confront, and at the time of adolescence retreated into the forced hibernation of the childish anorexic body to forestall these demands. Not only a daughter's ineptitude was implicated, but also the envious mother's relentless projection of her own unmet aspirations. An interpretation, of course, which too neatly packages the complex and difficult transition from the staunch ethics of the mid-20 $20^{\text {th }}$ century to the media-driven culture of narcissism in the 1970 s and 80 s.

Within the soothing pathos lurks a Bosch-like grotesquerie. Consequently I spent extra time on the gradual evolution of this collage, beginning with the isolated "ribcage" to suggest how a prison has been constructed both within and without, the anorexic body making manifest the condition of this tacit imprisonment. Having first intended to place the sparrow in the ribcage as a basic visual metaphor, as I began working with the large image of the kneeling woman, who is pinching the thin layer of fat over her ribs, I decided that the skeletal cutout, though more frontal, could be interestingly superimposed over the woman. She holds it gently like a shield-or a Halloween costume. The photograph of the blonde is one of a series in a "woman's encyclopedia" of the 70s, and illustrates a chapter on maintenance of the body 
beautiful. Anonymous experts recommend a strenuous but "rewarding" daily "discipline" of forty-five minutes of self-message as a defense against cellulite.

I included a disproportionately large caged canary in the background to emphasize the link to the original extended metaphor; I also noted that the yellow bird recalled my first pet parakeet and accompanying experience of death and guilt. Moreover, during my acute teenage anorexia, my parents bought me a second blue parakeet, which I unsuccessfully attempted to characterize as a magic sign for my recovery. So more blue entered the background, and the blue glass ribbing of the backdrop called to mind the ubiquitous fishbone of Surrealist Max Ernst-and how Dorothea Tanning (2001) has characterized their marriage's late moments of shared recollection as the tracing of the spine of a fossil. Then I added the split fillets of the trout, spread by the hands of the (remembered? fantasized?) lover/healer, which now merge into the thighs of the woman.

As the comments above suggest, this glamourous image triggers in me a profound nostalgia and mourning for the lost adolescent body and potential, while dramatizing the unitary denial of its loss, the urge to control and preserve, to silence competing voices. Gold for the blended childhood impressions of urine, honey, beer, and sunshine, for the Golden Age of youth in the year of Expo '67, for Midas's condemnation to starvation, for the eggs of the magical goose which was cut open and found empty. Nothing gold can stay. Trying to insert more empty eggshells in the fish, I could not resist the tidy fit of the pinkish-grey, intact clutch. The last additions were the other small birds: The woodpecker hammering home the message, the bunting inside the ribs, the parrot, yellow finch, and-almost unnoticeably tiny, inaudiblethe bluebird of the impossible, happiness and omen. Multiple voices of instruction, instinct and sensation, within and without. Moreover, at this point my texts/collages became increasingly multivocal, my anecdotal memories one voice among the citations of theorists and recovered anorexics, and the detached theoretical musings of the academic self. 


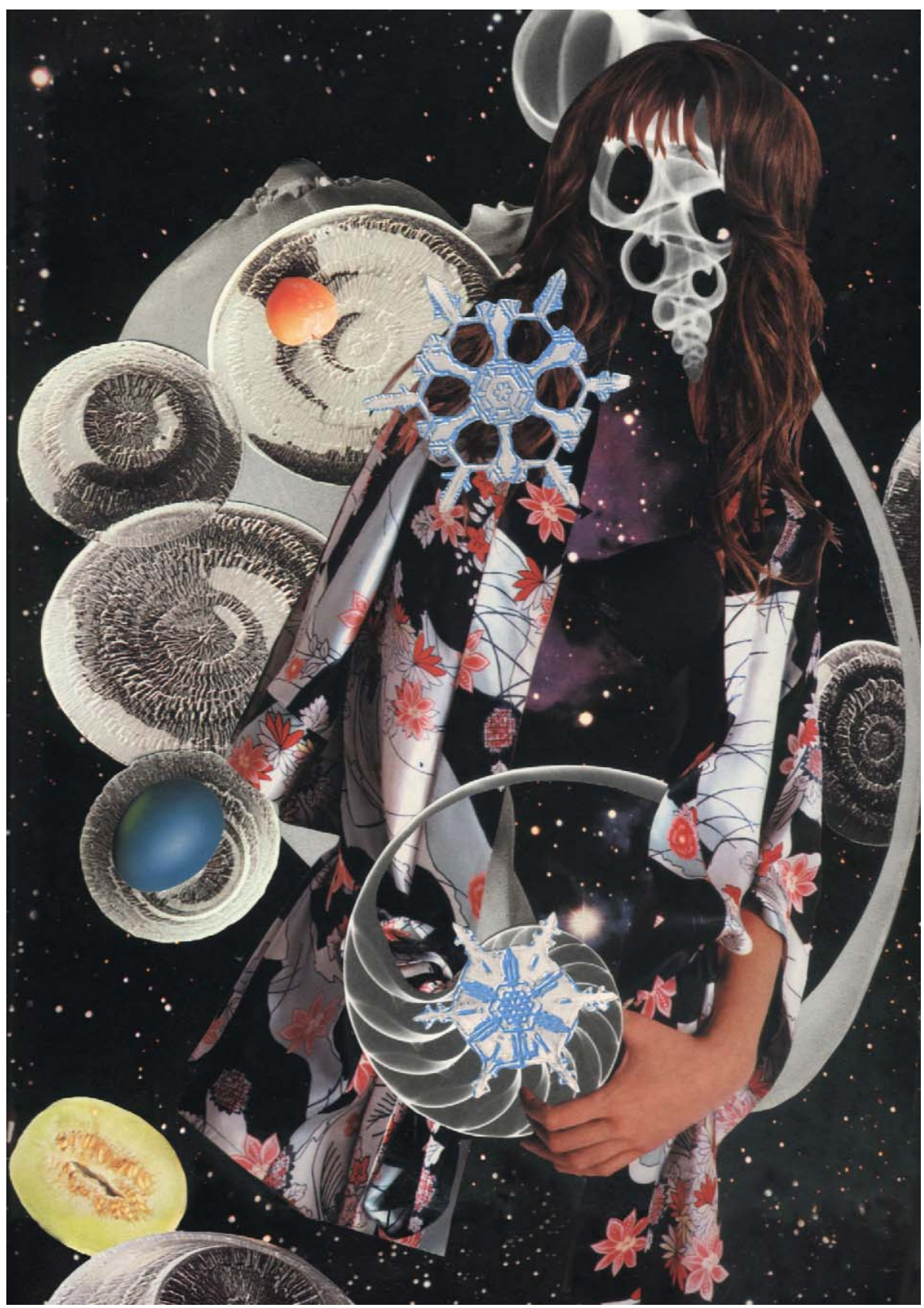

Fig. 5: Nature abhors a vacuum

I had read a magazine article in which a recovered anorexic spoke of the pursuit of the perfect zero-a clothing size, but also a powerful metaphor of the 
vacuous and otherworldly perfection that the enviable thinness of the anorexic body may appear to offer to a girl struggling with feelings of worthlessness and inadequacy. In its extreme form, such a goal becomes metaphysical, as if one could divest the physical body entirely and stand by its side as pure spirit. Such a profound wish may be credited with the long series of rescues, sometimes terminated in accidental death or suicide, that characterize anorexia in its acute phases.

Less evident, though clearly discerned by Bruch, is the fact that anorexia, untrue to its name, is not a state of "no appetite" (Bruch, 1978). The anorexic's hunger for experience, in contradiction to her weakened material grasp on the world, is immense, not in the least because severe or prolonged deprivation temporarily sharpens sensation and perception. But just as psychic disorientation produces perceptual distortions of the body image, so space and time arise in the anorexic view as perilously vast and unformed, a chaos which must be filled with a bewildering array of objects, intentions, and plans, often listed just as meticulously as the amounts of food eaten and their calorie counts.

In the later collages I am often chasing this fugitive equilibrium, seeing just how much elaboration, how much detail and surfeit, the chaste rectangle of the picture may bear before it dissolves into visual cacophony and illegibility. Before, in all its complexity, it nonetheless reverts to the blissful state of perfect zero... which is also, paradoxically, Dionysian oblivion. Here I believe the layering inherent to the collage has achieved profound results, communicating the sense of groundlessness, the lack of a stable self persisting through place and time, which underlies the food obsessions and starvation panics of eating disorders. Instead, there is the incoherence of desire and the emptying out of interior contents, regulated and replaced by small portions of food counted out meticulously and distributed to constitute manageable units of time. While the media imagery continues to constitute or present an inflated, spectacular sense of self, there is a visible movement from the beautiful, intoxicating and celebratory moments of a culture which prizes and values anorexia as an extraordinary performance of its professed values, to a visible emptying-out of all internal contents in the service of an addictive mechanism. By the very images that have constituted and supported it, the real effects of the chronic pursuit of the thin bodyphysical and psychic — are manifest in this ghost. Apparition — "the act of appearing." 


\section{Afterword/Conclusions}

The product of my collage and textual investigations is neither purely a case study, a confessional, a lifewriting, nor an illustrated theoretical paper. While it is admittedly a "research document" in progress, a "database" open to further critical and experiential investigation, it is also a multifarious, yet unified, poetic - and fantastic-body (of work). The disorientation and multiple perspectives of postmodern collage have converged on an intuitive whole, though one which may widely distribute the sense of agency and even selfhood among relationships and phenomena. Noteworthy is the evocation of telling memories and the illumination of obscure psychic and physical states, often through the effects of the peculiarly disturbing media references that seem to stand in for (if not replace) inarticulate emotions and desires; and the rapid progression from seemingly elementary, nominal categories to complex analogies and observations of anorexia as existential and cultural dilemma. Further self/body image investigations are indicated, to be accompanied by more extensive semiotic analysis and exploratory activity in collage as "figuration" of visceral and emotional experience, especially at the level of tactile operations as well as visual image-making.

My results strongly underscore the disturbing idea that waves of sociocultural imagery work on a level below or above the apprehension of visible denotation to communicate through all "incarnations" a few "master narratives": power- and valuedriven myths of presence and absence. More is required to pierce our cultural obsessions than the Internet distribution of a photograph of a vulnerable, naked anorexic actress. Collage, dissembling and ultimately inauthentic, captures and finally reveals the inauthenticity and false promise of the subject position into which the anorexic has-only more or less consciously-bought. At the same time, however, the methodology of collage illuminates the paradox of the eating disordered condition, in which an apparently rigid will patrols a sense of psychic and physical self that has become infinitely extensible, permeable, without borders; in which a stance of defiant exhibitionism is paired with an equal drive to disappear; in which internal and external, visible and invisible, symbolic and real, even life and death, are scrambled, exchanged, and confounded.

I hope that the intense sharing of my images and lifewriting may appeal to both academic and general readers in the field of education, recommending collage methods as means to alternative perceptions and reflections. Educators still strongly oriented to written culture may find in collage a means to precipitate a more con- 
scious understanding of the effects of our immersive multimedia environment. Inservice teachers, always powerfully grounded in concrete experience, intuitively understanding that one must show more than tell, are surely aware that traditional discussion and interpretation of visual imagery and media narratives does little to mitigate their impact; these are intimately internalized models, keyed into lived experience in unpredictable ways, that must be re-created, exorcised, and renegotiated on their own terms.

Weber and Mitchell, in their feminist theorizing of such touchstones of material culture as shoes and dresses, have moved from attention to the rhetorical/ metaphorical implications of clothing to delve deeply into the ritual enactments and embedded symbolizations involved in the draping of the gendered body (Weber \& Mitchell, 2004). Ultimately one thinks not only through the art process but also through a web of rhetorical identifications, associations and cultural/historical contexts, a project which may be driven less by "representation" than by "figuration," and performativity - the attributes of an art medium being mapped metaphorically onto diverse activities to evoke a radical jouissance. Perhaps collage thus offers a parallel means in which to rethink and reengage the cultural struggles among image, body, and self; an opportunity to realize or liberate the unspeakable creative tensions locked into the eating disordered stance (Bordo, 1993; Garrett, 1999; Knapp, 2003). Through the collagist's weaving together of theory, personal memory and fantasy, and active creation, researchers and educators may imagine and identify an integral body, world and community even amidst the fragmented image-play of media ideologies. I would thus advocate a practice that implicates the power of the body/image in educative change and validates arts-informed methodologies in their opening of alternative spaces for learning and healing.

\section{References}

Bordo, S. (1993). Unbearable weight: Feminism, Western culture, and the body. Los Angeles: University of California Press.

Bruch, H. (1978). The golden cage: The enigma of anorexia nervosa. Cambridge, MA: Harvard University Press.

Burke, E. (2006). Feminine visions: Anorexia and contagion in pop discourse. Feminist Media Studies, 6(3), 315-330.
Butler-Kisber, L. (2006). Unpublished interview with Donna Davis. July, 2006, McGill University, Montreal, QC.

Davis, D. (2000). Collage as an alternative methodology for self-study: Reconstructing personal identity and experience in an artistic medium of representation. Unpublished Master's monograph, McGill University, Montreal, QC. 
Davis, D. (2004). Artist's statement (untitled). Graduate Certificate in Digital Technologies in Design Art Practice (graduating class exhibition, Concordia University). April 2004, Galerie In Vivo, Montreal, QC.

Davis, D. \& Butler-Kisber, L. (1999). Arts-based representation in qualitative research: Collage as a contextualizing analytic strategy. Paper presented at the Annual Meeting of the American Educational Research Association, Montreal, QC (April). Resources in Education, 34, 135 (ED 431 790).

De Bono, E. (1999). New thinking for the new millennium. London: Viking.

Eisner, E. (1991). The enlightened eye. New York: Macmillan.

Eisner, E. \& Barone, T. (1997). Arts-based educational research. In Richard M. Jaeger (Ed.), Complementary methods for research in education. Washington, DC: AERA, 73-99.

Farb, P.\& Eds., Time-Life Books. (1971). Life Nature Library: The insects. New York: Time-Life Books, 66-69.

Ferris, J. (2003). Parallel discourses and 'appropriate' bodies: Media constructions of anorexia and obesity in the cases of Tracey Gold and Carnie Wilson. Journal of Communication Inquiry, 27:3, July, 256-274.

Garrett, C. (1998). Beyond anorexia: Narrative, spirituality, and recovery. Cambridge, UK: Cambridge University Press.

Hebdige, D. (1979). Subculture: The meaning of style. London: Routledge.

Hinz, L. (2006). Drawing from within: Using art to treat eating disorders. London: Jessica Kingsley Publishers.

Inch, R. \& Morali, N. (2006). A content analysis of popular magazine articles on eating disorders. Eating Disorders, 14:2, March/April, 109-120.

Kentridge, W. (2004). In praise of shadows. In William Kentridge. Milan: Castello di Rivoli, Museo d'Arte Contemporanea in association with Skira, 151-161.
Knapp, C. (2003). Appetites: Why women want. New York: Counterpoint.

Kuspit, D. (1983). Collage: The organizing principle of art in the age of the relativity of art. In B.J. Craige, (Ed.) Relativism in the arts. Athens: University of Georgia Press, 503-520.

Malson, H. (1998). The thin woman: Feminism, poststructuralism, and the social psychology of anorexia nervosa. London: Routledge.

Mastronardi, M. (2006). After Ophelia: Popular culture and female adolescence in crisis. Chicago: University of Chicago Press.

Ripa di Meana, G. (1999). Figures of lightness: Anorexia, bulimia, and psychoanalysis. London: Jessica Kingsley Publishers.

Rose, G. (2001). Visual methodologies: An introduction to the interpretation of visual materials. Thousand Oaks, CA: Sage.

Saukko, P. (2006). Rereading media and eating disorders: Karen Carpenter, Princess Diana, and the healthy female self. Critical Studies in Media Communication, 23:2, 152-169.

Shade, L. (2003). Weborexia: Ethical issues surrounding Pro Ana web sites. Computers \& Society, 33(4), (December), 2.

Tanning, D. (2001). Between lives: An artist and her world. New York:W.W. Norton.

Taylor, B. (2004). Collage: The making of modern art. London:Thames and Hudson.

Vaughan, K. (2005). Pieced together: Collage as an artist's method for interdisciplinary research. International Journal of Qualitative Methods, 4 (1) (March), 1-21.

Weber, S. \& Mitchell, C. (1995). That's funny, you don't look like a teacher!: Interrogating images and identity in popular cultures. London: Falmer Press.

Weber, S. \& Mitchell, C. (Eds). (2004). Not just any dress: Narratives of memory, body, and identity. New York: Peter Lang. 


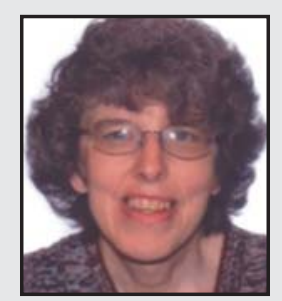

Donna Davis is a Montreal-based artist, working in graphic design while maintaining a studio practice in collage, drawing, and digital media. Donna coauthored a pivotal paper on the use of collage in arts-informed research, conducted action research in collage methodology, and was an instructor in the American Educational Research Association pre-conference workshops in 2005. She is also a former faculty member of the Saidye Bronfman Centre in Montreal.

LINKTO:

www.thevisualtext.com/mywordpress

www.thevisualtext.com/portfolio1/illustration/main.php 